\title{
Laser therapy applied to orofacial motricity: perception of members of the Brazilian Orofacial Motricity Association - Abramo
}

Asenate Soares de Matos(1) Giedre Berretin-Felix ${ }^{(1)}$

Rafael Nóbrega Bandeira(2) Jully Anne Soares de Lima(2) Larissa Nadjara Alves Almeida(2) Giorvan Ânderson dos Santos Alves ${ }^{(2)}$

(1) Universidade de São Paulo, Faculdade de Odontologia de Bauru, Bauru, SP, Brasil.

(2) Universidade Federal da Paraíba, João Pessoa, PB, Brasil.

Conflict of interest: Nonexistent

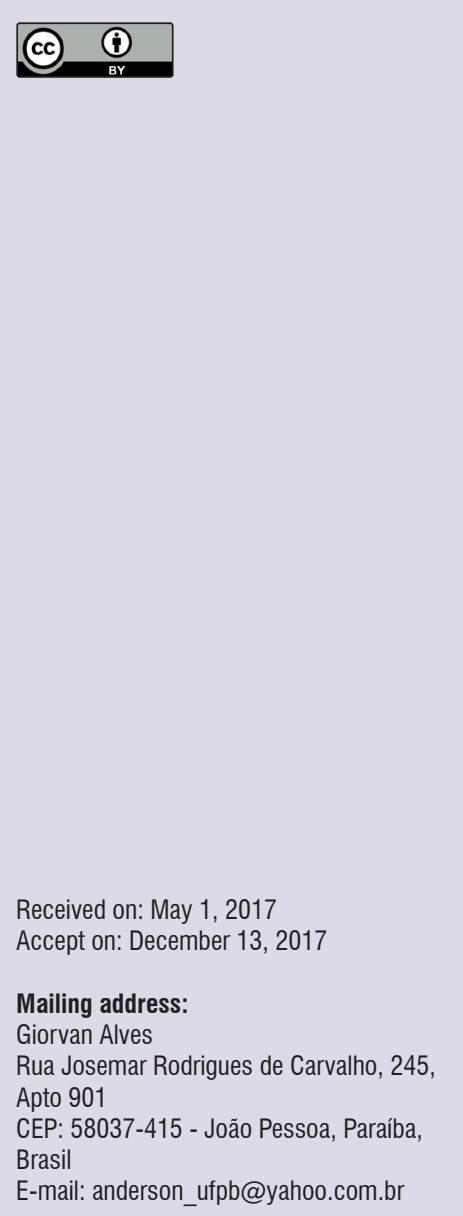

\section{ABSTRACT}

Purpose: to know the profile of members of the Brazilian Association of Orofacial Motricity and their knowledge and interest on laser therapy in Orofacial Motricity.

Methods: an online form was elaborated covering questions about the speech therapist's profile, training, and acting, as well as his/her knowledge about the theories of laser therapy and its clinical application. The form was sent via e-mail to members of the Brazilian Association of Orofacial Motricity - ABRAM0, registered in the year 2015. Data were analyzed through descriptive statistics and the Spearman's correlation test.

Results: only 5 (19.2\%) out of the 26 participants reported having contact with laser equipment, and of these, only 1 (3.8\%) used it in his/her practice. Regarding knowledge of the method, only $2(7.7 \%)$ were trained, and the majority, 14 speech therapists (53.8\%), had an interest in acquiring knowledge on this subject. Speech therapists with a longer training period were unaware of laser therapy $(p=0.03)$ and did not agree on the use $(p=0.01)$, but claimed to be interested in the subject $(p=0.05)$.

Conclusion: it was possible to verify that the interest in improvement and insertion in the clinical practice in laser therapy are realities for the research volunteers, but a very small number has the knowledge and makes use of the technique in their interventions.

Keywords: Low-Level Light Therapy; Laser Therapy; Speech, Language and Hearing Sciences; Speech Therapy 


\section{INTRODUCTION}

The term Laser is an acronym for Light Amplification by Stimulated Emission of Radiation. Its application in the health area has been studied as a therapeutic modality for rehabilitation, through non-invasive photophysical and photochemical modifications. The laser heats the stimulated site ${ }^{1-5}$, which occurs through the wavelength used in the electromagnetic spectrum, which goes from red to infrared light, visible and invisible, respectively ${ }^{1,6}$. The wavelengths most used in clinical practice are $600 \mathrm{~nm}$ to $1000 \mathrm{~nm}$, a determining factor for light penetration and absorption in contact with the tissue ${ }^{3}$.

The application of light for therapeutic use was first studied by Einstein in the $19^{\text {th }}$ century ${ }^{4}$, when he began to expose and explain about quantum therapy and stimulated light emission. After several studies, low-level lasers, whether of red or infrared emission, started being used in therapy.

The laser is a very specific type of electromagnetic radiation, which has very typical properties, differing from the light emitted by standard incandescent generators ${ }^{7}$. There are various types of lasers, with different definitions regarding wavelength, wave depth, and application ${ }^{6}$.

The laser has particularities such as the amount of energy and wavelengths that are adequate to penetrate the tissues and exert an effective influence on the synthesis, release, and metabolism of various substances involved in analgesia, for example ${ }^{2}$.

Laser therapy is a therapeutic modality that is being increasingly studied and reviewed in the academic field $^{7-9}$, since low-level laser is a non-invasive procedure which can biostimulate the irradiated area, that is, stimulate cell processes to obtain positive results.

The anti-inflammatory action after laser therapy is shown to be very efficient. Moreover, it increases the production of substances responsible for pain blockade, such as endorphins, and in areas with increased muscle tension it leads to increased blood circulation ${ }^{10}$.

Among the several satisfactory therapeutic effects that result from the irradiation of low-level laser therapy, the following can be cited: relief of painful symptoms, that is, analgesic, anti-inflammatory, and modulator effect of cellular metabolism 2,10-12. Treatment with this therapeutic modality can lead to a significant improvement in the pain level and mouth opening in patients affected with myogenous Temporomandibular Dysfunction $(\mathrm{TMD})^{3}$, as well as to a greater muscle balance when associated with orofacial motor exercises used in speech therapy ${ }^{13}$.

Laser therapy, in addition to being indicated for pain relief in patients with TMD, provides significant and satisfactory results when associated with manual therapy, and may be indicated as an effective, low-cost, non-invasive therapeutic method for this group of patients ${ }^{2,5}$, leading to a significant improvement in pain level and maximum mouth opening ${ }^{3}$.

The Speech Therapist specialized in Orofacial Motricity, or with a vast scientific clinical experience in the area, is trained in the study, research, prevention, evaluation, diagnosis, development, habilitation, improvement, and rehabilitation of the structural and functional aspects of the orofacial and cervical regions ${ }^{14}$ by means of several therapeutic modalities, which includes low-level laser therapy. Notwithstanding, since it is an area that is still of little knowledge and use, it is fundamental that the professional, besides being trained and having the ability to handle the equipment ${ }^{15}$, presents physiological and anatomical knowledge, in addition to knowing the benefits and counter-indications of treatment with laser therapy, aiming for a good clinical practice including the use of the technique ${ }^{16,17}$.

Since there are few studies in the scientific literature addressing the use of laser therapy and it is not yet a common practice for specialists in orofacial motricity, one should ask: What is the opinion of members of the Brazilian Orofacial Motricity Association (ABRAMO) on the insertion of low-level laser associated with speech therapy in the clinical practice of Orofacial Motricity?

ABRAMO is a civil non-profit association that emerged from the initiative of a group of speech therapists with an interest in scientifically deepening the field of Orofacial Motricity nationally and internationally. The association aims to promote Orofacial Motricity in Brazil through social actions, national and/or international meetings, as well as to improve the area.

Thus, the objective of this work is to know the profile of partners of the Brazilian Association of Orofacial Motricity and their knowledge and interest on laser therapy in Orofacial Motricity.

\section{METHODS}

This study was submitted to the approval of the Ethical Committee for Research with Human Beings of the Health Sciences Center of the Federal University of Paraíba, through the CAAE opinion: 43843715.2.0000.5188 and verification number 028738/2015. 
This is an observational study, since the researchers did not behave so as to interfere with the final result of the cross-sectional study; the volunteer's participation occurred in a unique period of time and field.

As eligibility criteria, the participants should be speech therapists and members of the Brazilian Association of Orofacial Motricity (ABRAMO).

The 2015 register of members of the Brazilian Association of Orofacial Motricity (ABRAMO) was used, from which the e-mail address of all 55 speech therapists was obtained. E-mails containing the invitation to participate in the research and the Free and Informed Consent Term (TCLE) were sent. Fifteen and thirty days after the first invitation e-mail to participate in the research, the second and third e-mails were sent, respectively, reinforcing the participation of professionals who had not responded to the questionnaire in previous attempts. Of the 55 invitations sent, 26 participated in responding to the questionnaire, of which 25 $(96.2 \%)$ were female and one (3.8\%) was male.

The study was carried out with the adaptation of a form that was developed based on the research of authors of the dentistry area ${ }^{18}$, covering 26 questions about the speech therapist's profile, training and performance data, and knowledge about laser therapy with objective questions. This was sent electronically, in an e-mail explaining the research, together with the FICT, containing the objectives, methodology, and information of the Ethical Committee for Research. By agreeing to participate, they were referred to the Google Forms website to complete the questionnaire.

For data analysis, the following were used: descriptive statistics, Shapiro-Wilk normality test, and Spearman's correlation test, since data normality was not obtained. For all tests, the significance level of $5 \%$ $(p<0.05)$ was considered. Data analysis and organization was performed through the software Statistical Package for Social Sciences (SPSS), trial version 22.

\section{RESULTS}

Of the 55 professionals associated with ABRAMO, until February 15, 2016, only 26 (47.2\%) answered the questionnaire.

The age range of the population studied varied from 31 to 70 years, with a mean age of 43 years; it was observed that most specialists are at least 41 years of age, and female (Table 1).

Table 1. Sample characterization data

\begin{tabular}{cccc}
\hline & & $\mathbf{n}$ & $\%$ \\
\hline \multirow{3}{*}{ Age range } & 31 to 40 years & 8 & 30.8 \\
& 41 to 50 years & 11 & 42.3 \\
& 51 to 60 years & 6 & 23.1 \\
& 61 to 70 years & 1 & 3.8 \\
Sex & Female & 25 & 96.2 \\
& Male & 1 & 3.8 \\
\hline
\end{tabular}

$\mathrm{N}=$ number; $\%=$ percentage 
Table 2 shows the distribution of the professionals surveyed regarding training and professional performance. Most have more than 20 years of training and are specialized only in Orofacial Motricity. Specialists reported to act on classrooms, clinics or internships, teaching in undergraduate and postgraduate courses.

Table 2. Training and professional experience data

\begin{tabular}{|c|c|c|c|}
\hline & Training and professional experience & $\mathbf{n}$ & $\%$ \\
\hline & Between 1 and 5 years & 0 & 0 \\
\hline Time since graduation in Speech & Between 6 and 10 years & 1 & 3.8 \\
\hline \multirow[t]{3}{*}{ Therapy } & Between 10 and 20 years & 11 & 42.3 \\
\hline & From 21 years & 14 & 53.8 \\
\hline & Doctorate degree & 16 & 61.5 \\
\hline \multirow{5}{*}{ Background } & Master's degree & 7 & 26.9 \\
\hline & Specialization & 2 & 11.5 \\
\hline & Graduation only & 0 & 0 \\
\hline & Orofacial motricity & 21 & 80.8 \\
\hline & Orfacial motricity and language & 2 & 7.7 \\
\hline \multirow[t]{3}{*}{ Area of Expertise } & Orofacial motricity and dysphagia & 1 & 3.8 \\
\hline & Language and voice & 1 & 3.8 \\
\hline & Not mentioned & 1 & 3.8 \\
\hline \multirow{3}{*}{ Experience in more than one area } & Yes & 13 & 50.0 \\
\hline & No & 13 & 50.0 \\
\hline & Does not teach & 3 & 11.5 \\
\hline \multirow{4}{*}{ Teaching in Speech Therapy } & Teaches in undergraduate courses & 6 & 23.1 \\
\hline & Teaches in postgraduate courses & 8 & 30.8 \\
\hline & Teaches in both courses & 9 & 34.6 \\
\hline & Does not teach in postgraduate courses & 8 & 30.8 \\
\hline \multirow{5}{*}{ Postgraduate teaching } & Latu Sensu & 12 & 46.2 \\
\hline & Strictu Sensu & 5 & 19.2 \\
\hline & Both & 1 & 3.8 \\
\hline & Classroom & 3 & 11.5 \\
\hline & Clinic and/or internship & 5 & 19.2 \\
\hline \multirow{4}{*}{ Workplace } & Other places & 2 & 7.7 \\
\hline & Classroom, Clinic and/or internship and Other places & 3 & 11.5 \\
\hline & Clinic and/or internship and Other places & 1 & 3.8 \\
\hline & Classroom and Clinic and/or internship & 12 & 46.2 \\
\hline
\end{tabular}

$\mathrm{N}=$ number; $\%$ = percentage

Table 3 presents data on the knowledge about laser therapy applied to Speech Therapy. Most of the speech therapists surveyed indicated that they knew laser, but did not have access to laser therapy equipment and/ or experience with this practice, and did not acquire knowledge in undergraduate and postgraduate courses. Furthermore, most professionals said they did not know the biosafety standards needed for the application of laser therapy. 
Table 3. ABRAMO members' responses on laser therapy applied to Orofacial Motricity

\begin{tabular}{lccc}
\hline & Responses & $\mathbf{n}$ & \% \\
\hline Do you know what laser is? & Yes & 24 & 92.3 \\
& No & 2 & 7.7 \\
Do you have access to laser? & No & 21 & 80.8 \\
& Yes & 5 & 19.2 \\
Do you use laser therapy in your clinical practice? & No & 25 & 96.2 \\
& Yes & 1 & 3.8 \\
Do you have a particular laser device? & No & 26 & 100.0 \\
& Yes & 0 & 0 \\
Do you have a laser device in the institution where you teach? & No & 12 & 46.2 \\
& Yes & 6 & 23.1 \\
Did you acquire knowledge about laser therapy at & Does not teach & 6 & 23.1 \\
undergraduate level? & Does not know & 2 & 7.7 \\
Did you acquire knowledge about laser therapy at postgraduate & No & 26 & 100.0 \\
level? & Yes & 0 & 0 \\
Did you acquire knowledge about laser therapy in any course? & Yes & 25 & 96.2 \\
& No & 1 & 3.8 \\
Are you interested in acquiring knowledge about laser therapy? & Yes & 24 & 92.3 \\
Did you have access to any literature related to laser therapy & Yes & 2 & 7.7 \\
applied to speech therapy?? & No & 19 & 73.1 \\
Do you know the biosafety standards on laser therapy applied & Yes & 7 & 26.9 \\
to speech therapy? & No & 16 & 61.5 \\
In which therapeutic indications would/do you apply laser & Yes & 10 & 38.5 \\
therapy? & Temporomandibular & 20 & 76.9 \\
Do you agree that the Orofacial Motricity specialist should work & Facial Paralysis & 6 & 23.1 \\
with laser therapy? & Both & 12 & 46.2 \\
\hline
\end{tabular}

$\mathrm{N}=$ number; $\%=$ percentage

Table 4 shows the results of the Spearman's correlation test, in which it was possible to identify that the longer the professional experience, the lower the knowledge about laser therapy. In addition, it was observed that the longer the time since graduation, the greater the probability of the professional not agreeing with the use of this technique in speech therapy. 
Table 4. Spearman's correlation test results

\begin{tabular}{lcc}
\hline & Correlation & P value \\
\hline Time since graduation in Speech Therapy X Knows what laser is & -0.417 & 0.034 \\
Time since graduation in Speech Therapy X Interest in acquiring knowledge & 0.389 & 0.050 \\
about laser therapy & & 0.015 \\
Time since graduation in Speech Therapy X Agrees that the Orofacial & 0.471 \\
Motricity specialist should act with laser therapy \\
$\begin{array}{l}\text { Access to laser X Had access to any literature related to laser therapy applied } \\
\text { to speech therapy } \\
\begin{array}{l}\text { Access to laser X Knows the biosafety standards on laser therapy applied to } \\
\text { speech therapy }\end{array}\end{array}$ \\
\hline
\end{tabular}

$\mathrm{P}=<0,05$

\section{DISCUSSION}

The health professional needs to update his/her practice and be constantly improving in the various therapeutic modalities, and laser therapy has been the target of research for presenting very positive results. Despite the different methodologies for laser application, the reviewed research show that low-level laser demonstrates to be effective $e^{2,4-6,9,10,15}$. In view of the studies, we can affirm that laser therapy is a non-invasive, low-cost treatment modality that has been used in physiotherapeutic and dental practice to relieve pain, as well as for tissue regeneration ${ }^{7,10,11}$. There is also scientific evidence in the field of speech therapy on the effects of laser therapy associated with orofacial motor exercises, through a study of the association of these two modalities of intervention, with results that bring an important muscle balance, showing that this may be a new option in speech therapy ${ }^{13}$. These data reveal that the practice of laser therapy in Orofacial Motricity may become an option for speech therapy when combined with other treatment practices.

In the present study, the sample consisted of 26 professionals, mostly (96.2\%) females, with ages ranging from 31 to 70 years, and a mean age of 43 years. Regarding the training and professional performance, the questionnaire reveals that the speech therapists who participated in the survey responding to the questionnaire have, in the great majority (53.8\%), 21 years or more of performance and/or graduation time, and $16(61.5 \%)$ hold a doctorate degree.

The results of this study also evidenced the predominance $(80.8 \%)$ of specialists in Orofacial Motricity, which was expected given the profile and characteristics of the association investigated. This reveals an important position for speech therapists, since it is a Scientific Association of national reference for specialists in Orofacial Motricity. The Brazilian Association of Orofacial Motricity (ABRAMO) is a registered, non-profit group of professionals and researchers in national and international Orofacial Motricity (OM). This association aims at the development of $\mathrm{OM}$ as a science, in the national and global scene, through Actions, Promotions, Congresses, and Courses in the area.

Regarding questions related to laser therapy, 24 (92.3\%) professionals reported knowing what laser is. From this datum, it is possible to infer that at some point they obtained access to knowledge and/or even some practice with laser therapy. On the other hand, only 5 (19.2\%) had access to laser therapy equipment, and only $1(3.8 \%)$ used laser therapy in clinical practice. In this perspective of laser therapy data, the professionals stated that they did not study subjects related to laser therapy in the undergraduate program (100.0\%), and the vast majority (96.2\%) also reported not having had laser therapy contents or contact with the equipment in postgraduate courses. These findings demonstrate that the access to the knowledge of the laser therapy approach associated with speech therapy is quite scarce, since it is a recent and innovative clinical procedure approach, requiring improvements for applicability in Orofacial Motricity interventions. Given all the above, what we found in the literature becomes evident, few studies on the use of laser therapy applied to speech therapy areas.

The results of the Spearman's correlation test have identified that the longer the professional experience, the shorter the knowledge about laser therapy and the greater the interest in improving the profession. As the use of low-level laser is a recent technique in the clinical practice of health professionals, it is common to find speech therapists who have had neither content 
nor debate regarding low laser approaches in their undergraduate and postgraduate training, reflecting the correlation of the longer the time, the lower the knowledge, resulting in greater interest in taking improvement courses in the area.

The results indicated that professionals with a longer professional experience were associated with a greater probability to disagree with the use of laser therapy by speech therapists $(p=0.015)$, which leads us to think whether this could reflect the lack of opportunity for improvements in the subject or the lack of direct contact with the technique. Within the professionals that have access to laser, the probability of having access to some bibliography related to the subject is greater $(p=0.034)$, as well as a better knowledge of the Biosafety standards used for the application of the technique $(p=0.029)$. Professionals who know about laser have reported studying the subject and following the biosafety rules properly.

Laser therapy radiation acts as a biomodulatory agent capable of promoting anti-inflammatory and analgesic effects through induction of systemic and cellular responses ${ }^{11}$. It is important to emphasize that the patient's feedback in the treatment will not only depend on the type of laser, but also on the tissue under radiation, as well as on the patient's immunological conditions. It is known that in most cases, the best result is reached when the therapies are associated, which means that laser therapy can contribute satisfactorily with myofunctional orofacial therapy and cervical therapy.

The basic principles of laser therapy need to reach a greater number of professionals, so that the scientific evidence and the biosafety norms that are necessary for the application of this technique are well spread, resulting in a good applicability in the clinical practice of Orofacial Motricity.

In order for laser therapy to be used as a therapeutic modality in the area, it is important to use its techniques appropriately, covering specific knowledge about the dosimetry, wavelength, and energy density, according to the therapeutic objectives. However, it is worth mentioning that, like any new approach involving technologies, improvements of the equipment used are necessary, as well as constant updating in the clinical and laboratory findings, and mainly scientific evidences that prove the clinical efficacy.

When we raised questions about the approach, most of the subjects $(73.1 \%)$ showed interest in acquiring knowledge on the subject, since only $7.7 \%$ took a course. At the end, the professionals (76.9\%) agreed to the possibility of working with laser therapy.

In this study, it can be observed that most professionals confirm in their answers that they have restricted knowledge and show interest in improving in the area. Therefore, introducing improvements may provide specialists in Orofacial Motricity with the knowledge of the technique, its results and benefits, and a decision-making power whether or not to use it in clinical practice. All this with enough certainty that more scientific evidence will be necessary to subsidize a better procedure in the clinical practice of Orofacial Motricity, since $76.9 \%$ of ABRAMO members agree with the possibility of this new clinical practice.

\section{CONCLUSION}

Most ABRAMO members participating in the research do not use laser in their clinical practice, and did not obtain knowledge on the subject at undergraduate and postgraduate courses. It was found that the longer the professional experience, the lower the knowledge about laser therapy and the greater the interest in improving in the area. The professionals who have contact with the laser equipment are more likely to have access to the literature related to the subject and greater knowledge about the Biosafety standards used for the application of the technique. Finally, it was seen that most ABRAMO members agree that Orofacial Motricity and Speech Therapy should adopt this new technique in their procedures when necessary and indicated, as a complementary form of treatment.

\section{REFERENCES}

1. Rocha J. Terapia laser, cicatrização tecidual e angiogenese. RBPS. 2004;17(1):44-8.

2. Andrade TNC, Frare JC. Estudo comparativo entre os efeitos de técnicas de terapia manual isoladas e associadas à laserterapia de baixa potência sobre a dor em pacientes com disfunção temporomandibular. Rev Gauch Odontol. 2008;56(3):287-95.

3. Ahrari F, Madani AS, Ghafouri ZS, Tuner J. The efficacy of low-level laser therapy for the treatment of myogenous temporomandibular joint disorder. Lasers MedSci. 2014;29(2):551-7.

4. Brochini APZ. Análise da contribuição do laser de baixa intensidade como terapia de apoio no tratamento de DTM com placa oclusal. [Dissertação]. Ribeirão Preto (SP): Faculdade de 
Odontologia de Ribeirão Preto da Universidade de São Paulo; 2012.

5. Frare JC, Nicolau RA. Clinical analysis of the effect of laser photobiomodulation (GaAs - $904 \mathrm{~nm}$ ) on temporomandibular joint dysfunction. Rev Bras Fisioter. 2008;12(1):37-42.

6. Matias AGC, Rocha AB, Santos CS, Fonseca MA. Modulação da dor em portadores de disfunções temporomandibular pela ação do laser - ASGAAL. Interscientia. 2014;2(2):25-37.

7. Henriques ACG, Cazal C, Castro JFL. Ação da laserterapia no processo de proliferação celular: revisão de literatura. Rev Col Bras Cir. 2010;37(4):295-302.

8. Venancio RA, Camparis CM, Lizarelli RFZ. Laser no tratamento de desordens temporomandibulares. JBA. 2002;2(7):229-34.

9. Venancio RA, Camparis CM, Lizarelli RF. Low intensity laser therapy in the treatment of temporomandibular disorders: a double-blind study. J Oral Rehabil. 2005;32:800-7.

10. Catão MHCV, Oliveira PS, Costa RO, Carneiro VSM. Evaluation of the Efficacy of Low-Level Laser Therapy (LLLT) In The Treatment of Temporomandibular Disorders: a randomized clinical trial. Rev. CEFAC. 2013;15(6):101-12.

11. Assis TO, Soares MS, Victor MM. O uso do laser na reabilitação das desordens temporomandibulares. Fisioter Mov. 2012;25(2):453-9.

12. Kato MT, Kogawa EM, Santos CN, Conti PCR. TENS and low-level laser therapy in the management of temporomandibular disorders. Journal of Applied Oral Science: Revista FOB. 2006;14(2):130-5.

13. Cusumano, BCZ. Efeito de exercícios motores orofaciais e laserterapia nos sintomas de desordem temporomandibular e funções orofaciais. [Tese] Ribeirão Preto (SP): Faculdade de Medicina de Ribeirão Preto da Universidade de São Paulo; 2016.

14. Conselho Federal de Fonoaudiologia. RESOLUÇÃO CFFa no 320, de 17 de fevereiro de 2006.

15. Santos TS, Piva MR, Ribeiro MH, Antunes AA, Melo AR, Silva ED. Laser therapy efficacy in temporomandibular disorders: control study. Braz J Otorhinolaryngol. 2010;76(3):294-9.

16. Gelain MC, Santos EL, Erthal V, Barros FS, Machado Neto V, Nohama P. Avaliação de equipamentos laser fisioterapêuticos de emissão contínua e baixa potência. Rev da Univ Vale do Rio Verde. 2014;12(1):560-71.
17. dos Reis MC, de Andrade EA, Borges AC, de Souza DQ, Lima FP, Nicolau RA et al. Immediate effects of low-intensity laser $(808 \mathrm{~nm})$ on fatigue and strength of spastic muscle. Lasers Med Sci. 2015;30(3):1089-96.

18. Zerbinati LPS, Pinto MAO, Santos RL, Lacerda RCS. Avaliação sobre o conhecimento do laser entre alunos e professores do curso de Odontologia da Escola Bahiana de Medicina e Saúde Pública. Rev Bahiana Odonto. 2014;5(1):5-21. 